\title{
A MEMÓRIA CONGELADA DO IMIGRANTE a solidariedade intergeracional dos japoneses e dos nikkeis no Brasil e no Japão atual
}

\author{
Rosa Ester Rossini
}

\begin{abstract}
Resumo: $\mathrm{O}$ artigo discute a solidariedade intergeracional dos migrantes japoneses e seus descendentes no Brasil, incluindo-se os nikkeis que retornaram para o Japão. Discute também a atual solidariedade existente entre os japoneses residentes no Japão, que não migraram para o Brasil. Palavras-chave: Migração. Dekasseguis. Solidariedade.

Abstract: The article discusses the Japanese intergenerational migrants' solidarity and their descendants in Brazil, being included the Nikkeis that came back to Japan. It's also discussed the current existent solidarity among resident Japanese in Japan, that didn't migrate to Brazil.

Key words: International migration. Remittances. Public Policies.
\end{abstract}

$\mathrm{A}$

população brasileira, nas últimas décadas, perdeu o ritmo histórico de crescimento, passando de $2,1 \%$ ao ano na década de 80 para $1,5 \%$ ao ano no período de 1990-2000 (IBGE, 2001; 2003a).

Hoje, além da pobreza, são muitas as linhas de atenção das pesquisas. Dentre elas destacamos:

- o aumento proporcional e numérico de idosos na população total. A população com 60 anos e mais correspondia, em 2000, a quase $9 \%$ do total (há municípios que chegam a 20\%; no distrito da Consolação, na cidade de São Paulo, era de $21 \%$ em 2004);

- a gravidez na adolescência;

- a morte de pessoas ainda jovens, do sexo masculino, na faixa de 15 a 39 anos, motivada por arma de fogo (chacina, extermínio), drogas e acidentes de trânsito, em particular de moto.

Na pirâmide populacional da cidade de São Paulo já pode ser identificada uma espécie de "dentes falhados" do lado masculino, nessa faixa etária. Em 1982, as taxas eram inferiores a 32 óbitos por 100 mil habitantes, atingindo o patamar de 125 óbitos em 1999. O número de óbitos de mulheres na mesma faixa etária era de 3 em 1980, passando a 7 por 100 mil habitantes em 2002 (FUNDAÇÃO SEADE, 2004).

A questão do desemprego/desocupação ocupa a atenção de todos os pesquisadores e das autoridades governamentais. Foram incrementadas algumas políticas como a do Primeiro Emprego, mas os resultados ainda são insuficientes em relação à demanda. As pessoas jovens não encontram trabalho porque têm que ter experiência. As pessoas com mais de 40 anos não encontram trabalho porque são consideradas velhas.

Devido à modernidade tecnológica, o mercado de trabalho se encolhe. Destaque-se que $70 \%$ dos bancários perderam os postos de trabalho nos últimos 15 anos. A saída é o setor terciário, em atividades informais (vendedor ambulante de tudo, desde frutas a eletroeletrônicos). Há também alguma chance como trabalhador autônomo, vendendo sua força de trabalho como elemento especializa- 
do, por alguns meses no ano. A pessoa terá mais oportunidade se for versátil e criativa. A outra possibilidade de conseguir trabalho é por meio da migração interna ou internacional. Além do telemarketing, o setor que hoje está empregando, mas em pequena escala, é o setor público especialmente o magistério. Esse é o motivo pelo qual houve aumento do número de homens que prestaram vestibular para ingresso na universidade em áreas mais voltadas para o ensino.

Do ponto de vista da migração, o Brasil, no século passado, passou por três fases distintas:

- até 1960, fase imigrantista - havia oferta de oportunidades de trabalho na agricultura e na nascente e progressista atividade industrial;

- de 1960 a 1980, fase emigrantista - as razões políticas foram as grandes motivadoras da partida das pessoas para o exterior;

- pós 1980, fase emigrantista - por razões econômicas, principalmente.

Estima-se que mais de 2,5 milhões de pessoas estejam fora do país (mais de $10 \%$ desse total encontram-se no Japão).

Nessa terceira fase, a migração internacional é basicamente de classe média ou média inferior. Em sua maioria, são migrantes com escolarização de nível médio que dispõem de capital para utilizar o meio de transporte rápido - avião (SASAKI, 1996; CAIADO, 1997; SALES, 1996)

No presente trabalho, é realizada uma discussão a respeito da solidariedade intergeracional dos migrantes japoneses e seus descendentes no Brasil. Incluem-se também, neste texto, os nikkeis (japoneses e seus descendentes) que retornaram/migraram para o Japão. Ao mesmo tempo, discute-se essa solidariedade vivida hoje pelos japoneses residentes no Japão que não migraram para o Brasil. São praticamente 100 anos de presença de japoneses e seus descendentes no Brasil: um século de uma memória congelada em relação à herança históricocultural vigente àquela época no Japão. Depois da Segunda Guerra Mundial, o Japão mudou muito e vive a "era dos descartáveis" para tudo - inclusive para as pessoas idosas.

\section{A VIAGEM DOS JAPONESES PARA O DESCONHECIDO}

Para melhor compreensão do Japão de hoje, torna-se necessário recuperar sinteticamente a história de seu povo e de sua gente.
Com a restauração Meiji (1868), a massa de desempregados aumentou em virtude da crise econômica e do desemprego real e potencial intensificado pela baixa produtividade agrícola e industrial. As medidas de modernização tomadas provocaram tensões sociais que redundaram na saída dos excluídos (YOSHIOKA, 1995).

Nessa época, a política imigratória brasileira convocava braços para a lavoura cafeeira, enquanto a política japonesa era a de apoiar os migrantes como pequenos proprietários.

Os primeiros migrantes (1908-1923) eram basicamente de origem rural e foram encaminhados para as fazendas de café (165 famílias - 786 pessoas).

Bastaram algumas semanas para os japoneses perceberem que o país que haviam escolhido pouco ou nada tinha a ver com o "Eldorado" que as agências encarregadas de organizar a imigração lhes haviam prometido no Japão. Estavam em um lugar cuja língua não entendiam, conviviam com um clima diferente, com gente que tinha costumes, religião e até rostos diferentes dos deles. $\mathrm{O}$ remédio era conformar-se, comer pouco, vestir-se mal e economizar dinheiro para o retorno. Ledo engano. O sonho, em sua maioria, não se realizou (FAUSTO, 1998).

O segundo período (1924-1941) foi o de destinação principal dos migrantes para núcleos coloniais, e com forte apoio do governo japonês.

As rígidas restrições impostas nos anos de guerra (em particular na 2 ${ }^{\underline{a}}$ Grande Guerra) aos japoneses residentes no Brasil tinham sido apenas um capítulo a mais no calvário de provações vividas por eles desde a época dos primeiros migrantes. As autoridades tinham preocupação com a formação de quistos; o governo estabeleceu o sistema de cotas em 1930; proibiu também o funcionamento de escolas de língua japonesa e levou à prisão aqueles que "desobedeciam" as normas estabelecidas. Acrescentem-se ainda os problemas criados entre os migrantes com a nãoaceitação da derrota do Japão na $2^{\underline{a}}$ Guerra Mundial.

O terceiro e último período, nos meados do século 20 , foi realizado via imigração planejada ou livre, viabilizada pela iniciativa particular de japoneses residentes no Brasil por meio das redes de parentesco e amizade, e pela chamada de órgãos diversos - como a Sociedade Paulista de Sericicultura, a Cooperativa Agrícola de Cotia, etc.

De 1908 a 1972, cerca de 250 mil pessoas de origem japonesa chegaram ao Brasil. Desse total, 75\% radicaramse no Estado de São Paulo.

Na cidade de São Paulo, os bairros étnicos representaram um fator de intimidade e segurança, em meio às vi- 
cissitudes da vida na cidade. Por exemplo, o japonês feirante - depois de enfrentar com seu mutismo os fregueses que regateiam insistentemente - retorna ao seu bairro, a Liberdade, com a sensação de intimidade e segurança (FAUSTO, 1998). É bastante conhecida, por exemplo, a frase dos feirantes japoneses ou mesmo de seus descendentes em resposta a fregueses que regateiam com insistência: "no entendo", como forma de encerrar o assunto.

A língua funciona também como forma consciente ou inconsciente de resistir à integração: número considerável de japoneses após 30, 40, 50 anos ou mais no Brasil, não entende português e a "língua oficial" em casa é a japonesa, com o objetivo de preservar a continuidade e a manutenção dos laços do país de origem.

Os imigrantes japoneses tinham o compromisso de honra de só retornarem ao Japão como vencedores. Não podiam sequer pensar em levar seus filhos nascidos aqui como gaijim. Era preciso que eles aprendessem a ler e a falar a língua japonesa. Esta era a maneira que eles encontraram de não terem seus filhos considerados como estrangeiros pelos japoneses, quando retornassem ao Japão (SAKURAI, 1987, p. 43).

Essa “doce ilusão", o sonho do retorno rápido, perdurou por muito tempo. A realidade aconteceu quando, nos anos 80, o Japão necessitou de mais braços e chamou seus patrícios para o trabalho.

Até que ocorresse esse chamado, os japoneses perceberam a dificuldade ou mesmo a impossibilidade de retornarem ao Japão. Dessa percepção decorreu a tendência de "aculturar-se" por meio da conversão formal ao catolicismo, da escolha de nomes cristãos para os filhos e do casamento com não-descendentes (FAUSTO, 1998).

A questão do casamento interétnico ocorre, num primeiro momento, com a união de uma brasileira com o primogênito da família japonesa. Explica-se tal tendência pelo fato de que a responsabilidade de assumir todos os encargos familiares na ausência ou dificuldade dos pais recaía, na tradição japonesa, sobre o filho mais velho. A organização familiar obedeceu a um sistema social hierárquico, organizado a partir do princípio de descendência patrilinear, no qual o filho mais velho é o herdeiro e o futuro chefe da família (TOMA, 2000). Por isso, as japonesas ou seus descendentes, sabedoras dessa responsabilidade e encargo, evitavam o casamento com o filho mais velho da família japonesa, tradição que de certa forma persiste até hoje, embora a miscigenação seja intensa entre os nikkeis de ambos os sexos no Brasil (ROSSINI, 2004).

Além da ocupação na agricultura, e mais tarde no comércio, os japoneses tiveram, no Brasil, uma enorme preocupação com a educação dos filhos como forma de ascensão social. No Brasil, a taxa de alfabetização de pessoas com 15 anos e mais, segundo o Censo Demográfico de 2000 , era de $87,1 \%$. Essa mesma taxa para a população amarela, em que predominam os japoneses, era de 95,1\% (IBGE, 2001; 2003a). Na Universidade de São Paulo, nos anos 80 e mesmo 90, cerca de $19 \%$ dos alunos eram de origem oriental, e aí se destacavam os de ascendência japonesa, em maior número, seguido dos chineses e coreanos. Frequientam e freqüentavam mais os cursos, principalmente, de exatas, tecnológicas e saúde. Menos de $1 \%$ da população brasileira é de ascendência japonesa. No Estado de São Paulo, a participação dos nikkeis na população total é inferior a 5\%.

A partir de 1970, quando houve a implantação de filiais de indústrias japonesas no Brasil ou a compra de indústrias nacionais pelos japoneses, iniciou-se um lento processo de imigração para o Brasil por parte dos japoneses, agora na situação de "técnicos especializados".

A título de exemplo de adaptação/integração, podem ser citadas informações a partir do último levantamento do Centro de Estudos Nipo-Brasileiro a respeito dos japoneses e seus descendentes no Brasil:

de cada dez descendentes, metade é casada com ocidentais [...] A mistura de raças é uma tendência irreversível. Estimase que existem 1,4 milhão de descendentes no Brasil. Desses, apenas 52 mil fazem parte da primeira geração de emigrantes. São mestiços cerca de 30\% (REVISTA MADE IN JAPAN, 2003).

Entretanto, deve-se destacar que $11 \%$ dos migrantes estrangeiros residentes no Município de São Paulo em 2000 eram japoneses, seguidos pelos italianos, que representavam 7\% (FUNDAÇÃO SEADE, 2004).

\section{A MEMÓRIA CONGELADA DO IMIGRANTE E SUA PRESENÇA EM UM OUTRO LUGAR}

O "lugar" é onde o indivíduo estabelece suas relações sociais, onde tem sua identidade e o sentimento de pertencer.

É no plano do cotidiano que vão aparecendo paulatinamente as formas de apropriação/utilização e ocupação de um determinado lugar do "mundo vivido". É assim que 
as relações se estabelecem na produção da existência das pessoas/famílias.

Já assentado no Brasil, o imigrante busca amenizar o corte, materializando, de várias formas, a lembrança da terra que deixou. Desse modo, o arranjo de sua casa tem características próprias, evidenciadas nos chamados objetos biográficos. Um retrato emoldurado de toda a família, um pôster turístico de um lugar do país de origem, uma imagem religiosa, etc., são expostos como fragmentos de um mundo a que se deseja voltar, mas que se suspeita jamais ser possível rever, ou, talvez pior, ao revê-lo não mais reconhecer seus traços originais (FAUSTO, 1998, p. 18).

O imigrante sente saudade do que deixou sem se dar conta, sem sequer racionalizar, sem perceber que o país de origem, no movimento dos acontecimentos socioeconômicos, científicos e políticos, sofreu profundas mudanças em relação à realidade de quando deixou aquele lugar. A memória congelada do país de origem, guardada preciosamente, mudou (FERREIRA, 2001). Mudaram os que ficaram; mudaram os que partiram, pois a sociedade e o espaço estão em contínuo movimento.

A mistura de raças, de etnias, é evidente em São Paulo e no Brasil. Todos sentem enorme orgulho de suas raízes históricas. Com frequiência, mesmo sem terem ido ao país de seus ancestrais, têm profunda curiosidade por tudo, especialmente a partir da história dos avôs/avós. Essa transmissão de conhecimentos/lembranças funciona como uma forma de não-apagamento da memória, como elo de ligação do passado com o presente.

A imigração representa um profundo corte, com vários desdobramentos, no plano material e no plano do imaginário.

O corte não é sinônimo de apagamento de uma fase passada, na vida individual, familiar ou do grupo, integrando-se pelo contrário ao presente, com muita força (FAUSTO, 1998, p. 4).

Atualmente, a maioria das migrações internacionais utiliza o avião como meio de transporte. As viagens duram muitas horas. Porém, o corte com a família, com o país, é aparentemente menos doloroso, pois os meios modernos de comunicação - telefone, Internet, correio encurtam as distâncias.

Nesse mundo globalizado é possível encontrar, até mesmo no lugar onde se está, todos os ingredientes para a receita da comida feita pela avó (bassan): só falta o "gostinho dado por ela à comida, aquele gostinho de algo que só ela sabia fazer e que tinha sabor de infância".

\section{A FACE DO BRASIL NO JAPÃO}

Os brasileiros que migram à procura de melhores condições de vida - "os deserdados do capitalismo" - na sua maioria não figuram nas estatísticas oficiais como migrantes: são "turistas". Há estimativas que apontam a existência de 250 mil a 310 mil migrantes do Brasil residindo no Japão. Muitos estão com a documentação em ordem, mas outros estão em situação irregular.

A Revista Made in Japan (2004) informa que o governo japonês realizou pesquisa sobre a vida dos brasileiros no Japão. São 268 mil, sendo:

- 52\% entre as idades de 20 e 40 anos;

- 68,6\% trabalham nas fábricas (economicamente ativos);

- 71\% são casados;

- 65\% estão há mais de cinco anos no Japão;

- 36\% das crianças estão fora da escola;

- 61\% ganham mais de 2 mil dólares mensais;

- nascem mais de 4 mil crianças por ano.

Os brasileiros constituem a terceira nacionalidade em número de estrangeiros no Japão, cifra somente superada pelos coreanos e chineses. A presença brasileira no contexto dos imigrantes da América do Sul é significativa. Os brasileiros são o grupo mais numeroso seguido de longe pelos peruanos (Tabela 1).

Em $1^{\circ}$ de junho de 1990 , foi aprovada a nova lei de controle de entrada de estrangeiros. As pessoas passaram a ter direito de contratar legalmente nisseis e sanseis. Mesmo após a regulamentação da referida lei, nem sempre os contratos são legais, apesar da existência de descontos de 15 a $30 \%$ do salário mensal dos chamados "contratados".

Em geral, os trabalhadores ilegais não percebem sua situação, ou só tomam consciência dela quando ficam doentes ou sofrem acidentes: seus contratos não são muito claros, seus direitos são raros.

Os autônomos devem efetuar o pagamento do seguro junto à prefeitura municipal. No caso de algum problema de saúde, deverão assumir $30 \%$ das despesas e não receberão pelos dias parados.

Em caso de doença, aqueles que são regulamente contratados pagam $10 \%$ das despesas com saúde e, após o quinto dia, recebem $60 \%$ do salário.

Os trabalhos dados aos nikkeis estão, segundo eles, na categoria dos 5 Ks: Kitsui (duro, pesado); Kitanai (sujo); Kiken (perigoso); Kibishü (exigente); Kirai (detestável) (FERREIRA, 2001). 
TABELA 1

Estrangeiros no Japão Provenientes da América Latina

$1991-2000$

\begin{tabular}{|c|c|c|c|c|c|c|}
\hline País & 1991 & 1992 & 1994 & 1996 & 1998 & 2000 \\
\hline Total & 151.798 & 185.704 & 201.843 & 246.187 & 271.398 & 309.230 \\
\hline Brasil & 119.333 & 147.803 & 159.619 & 201.795 & 222.217 & 254.394 \\
\hline Peru & 26.281 & 31.051 & 35.382 & 37.099 & 41.317 & 46.171 \\
\hline Argentina & 3.366 & 3.289 & 2.796 & 3.079 & 2.962 & 3.072 \\
\hline Paraguai & 1.052 & 1.174 & 1.129 & 1.301 & 1.441 & 1.678 \\
\hline Bolívia & 1.766 & 2.387 & 2.917 & 2.913 & 3.461 & 3.915 \\
\hline
\end{tabular}

Fonte: Yoshioka, (2002). Japan Immigration Association - JIA - Heisei 13.

Embora sejam de ascendência japonesa, não são muito aceitos pela sociedade local por não terem os mesmos hábitos e por não falarem a língua. São conhecidos como os "brasileiros" (FOLHA DE S.PAULO, 2003).

Na verdade, o que garante a permanência dos migrantes do Brasil no Japão é a solidariedade daqueles que vieram em primeiro lugar e a solidariedade da família que deixaram no Brasil.

\section{PARA MELHOR ENTENDER A SOLIDARIEDADE: ALGUNS DIREITOS DA PESSOA IDOSA NO BRASIL}

A partir dos anos 80, organismos internacionais, como a Organização das Nações Unidas e mais tarde a Comunidade Européia, tiveram um papel ativo na produção de novas sensibilidades em relação ao envelhecimento em diferentes culturas (DEBERT, 2004, p. 235).

A Constituição Brasileira de 1988 atendeu a alguns reclamos e necessidades da população idosa e o Estado brasileiro apoiou muitas das aspirações na Política Nacional do Idoso de 1994, que foi regulamentada em 1996. Nessa política, os campos de atuação dos idosos foram em parte reconhecidos.

Percebe-se certa atenção geral com o aumento de eventos sobre o tema, o destaque nos meios de comunicação, o cumprimento da legislação: são algumas das demonstrações da importância da pessoa idosa, hoje, no Brasil e no mundo.
De envelhecer ninguém escapa. Alguns envelhecem mais rapidamente do que outros e nem todos vivem essa etapa da vida da mesma maneira, uma vez que o envelhecimento biológico está estreitamente relacionado às formas materiais e simbólicas que identificam socialmente cada indivíduo (PEIXOTO, 1999, p. 357).

As questões ligadas ao envelhecimento, que antes eram adstritas ao mundo privado (médico, prática de caridade religiosa) alçam vôo, transformando-se em discussão mais ampla, instigando campos de conhecimento e do agir. Isto é, atinge a esfera do espaço público (CABRAL, 2001).

Esse prolongamento da vida tem mais a ver com rejuvenescimento/integração do idoso na sociedade do que com a efetiva discussão sobre o velho propriamente dito (CABRAL, 2001).

Tanto a demonstração de solidariedade da sociedade atual para com os idosos quanto o incentivo a essa prática sugerem a necessidade de se refletir sobre a construção das relações entre as gerações jovens e velhas no espaço público (das políticas públicas) e no espaço privado. A solidariedade deve ser pensada como uma totalidade profundamente imbricada, onde cada um compartilha com o outro em todos os momentos de vida, isto é, nas alegrias, nos problemas, etc. (CABRAL, 2001). A solidariedade pode salvar as pessoas reinserindo-as na sociedade e recuperando sua auto-estima.

As formas de solidariedade entre as gerações construídas no espaço público permitem identificar diferenciações entre essas formas e aquelas tecidas no interior do seio da família, 
onde as regras de reciprocidade se vinculam à consangüinidade e às relações de parentesco que envolvem os membros de várias gerações, estando muito mais presentes aspectos indicativos de uma relação de obrigações morais entre pais e filhos e mesmo entre aqueles e seus netos (CABRAL, 2001, p. 30).

A Constituição Brasileira, em particular após 1988, e outras formas de regulamentação posteriores impõem um conjunto de obrigações legais de proteção entre pais e filhos e vice-versa. A não-obediência pode ter graves conseqüências para aqueles que não atendem a esse ordenamento jurídico que formaliza e obriga os indivíduos com vínculos parentais ao exercício da solidariedade. Além disso, só o risco de ser punido elimina muitas incorreções por parte daqueles que pretendiam desobedecer as leis (BARROS, 1987; CABRAL, 1999; 2001).

A Constituição Brasileira de 1988 e a legislação posterior estabelecem, dentre outros itens, que:

- homens com 65 anos e mais, e mulheres com 60 anos e mais têm direito à aposentadoria de 1 salário mínimo (que era inferior a 100 dólares em 2004), por meio da Previdência Social Rural, mesmo sem terem contribuído. A legislação de 1963 estabelecia o benefício da aposentadoria (jubilamento/reforma) para apenas uma pessoa na família, em geral o homem e, em todos os casos, com apenas um salário mínimo vigente;

- as pessoas que contribuíram com outros valores e pagaram à Previdência, obviamente, têm direito à aposentadoria correspondente;

- haja transporte urbano gratuito - ônibus e metrô - para as pessoas idosas, sejam homens ou mulheres. Esse benefício possibilitou à pessoa idosa maior liberdade, maior autonomia, concorrendo para o aumento da esperança de vida. Com essa autonomia, nas famílias mais pobres a pessoa idosa passou a receber encargos que nem sempre eram exercidos por ela, como pagar contas, levar crianças à escola, etc.;

- a partir de 2004, o transporte interurbano e interestadual deveria ser gratuito para pessoas que recebessem até 2 salários mínimos mensais. Porém, essa medida tem sido boicotada, com freqüência, pelos responsáveis pelas empresas;

- haja assentos preferenciais nos transportes;

- haja guichês preferenciais para atendê-los nos bancos;

- haja guichês preferenciais nos aeroportos para atendimento aos idosos;
- em cinemas e teatros as bilheterias sejam preferenciais e com $50 \%$ de desconto;

- sejam implantadas Delegacias de Proteção ao Idoso;

- nos hospitais públicos seja reservado espaço para acompanhante da pessoa idosa (em geral é uma poltrona ao lado da cama). Essa é uma medida que favorece a solidariedade intergeracional e ainda evita a contratação, pelo hospital, de atendentes personalizados para pessoas altamente dependentes;

- na tramitação de processos seja assegurada a prioridade à pessoa idosa;

- em Brasília, capital federal, acrescenta-se ainda a reserva de 5\% das vagas para automóveis em áreas públicas ou privadas para uso da pessoa idosa.

Com a legislação para a pessoa idosa no Brasil, criaram-se duas novas categorias profissionais: office old e motobói. Assim, praticamente desaparece o office boy. Como os idosos não precisam aguardar na fila porque têm guichês especiais para a sua faixa etária, e também porque não pagam transporte e, além disso, já são aposentados, os serviços que antes eram feitos pelo office boy passaram a ser feitos por eles, pois representam benefícios econômicos para os contratantes.

Já os motobóis circulam aceleradamente por São Paulo fazendo entregas rápidas de mercadorias e papéis, comprometendo a própria vida. Há informações de que 280 mil motobóis circulam diariamente em São Paulo e que lamentavelmente ocorre, no mínimo, uma morte por dia desse profissional.

Por várias razões, a expectativa de vida da mulher é bem superior que a dos homens - e essa é uma tendência mundial. Em 2000, no Estado de São Paulo, por exemplo, a expectativa de vida das mulheres era de 75,6 anos, enquanto a dos homens era de 66,8 anos. Essa situação é reforçada, dentre outras razões, pela morte prematura dos jovens na faixa dos 15 a 35 anos, motivada por acidentes de trânsito (motos), arma de fogo e drogas. Assim é que foi cunhada a denominação de "feminização da velhice" (MOTTA, 1999a). No Brasil a mesma diferença existe em relação à esperança de vida (total 71,0; homens 64,8; mulheres 72,6 anos) (IBGE, 2001; 2003b; FUNDAÇÃO SEADE, 2003; 2004).

Outro assunto a ser analisado é a solidariedade das pessoas idosas no Brasil, que é demonstrada de várias formas. Entretanto, destaque-se que a presença feminina é marcante. As atividades realizadas pela pessoa idosa e as atividades de integração são: visitas às pessoas neces- 
sitadas; confecção de roupas para doentes e carentes; participação em grupos de dança, música, teatro; frequiência a festas, palestra, cursos; participação em grupos de ginástica, desenho; frequiência a cursos para aprendizado e uso do computador, da Internet, etc. Há, portanto, uma série de programas centrados na "sociabilidade programada e centrada no lazer e na cultura - e que são predominantemente femininos" (MOTTA, 1999a, p. 171). São pessoas atentas e abertas a novas amizades, as quais são cultivadas carinhosamente.

Contar história é uma prática que tem sido muito difundida por idosos e idosas no Brasil. É comum serem convidados por professores de seus netos para ir à escola contar as histórias que conhecem ou para falar sobre a cidade ou o campo. Essa prática não só reforça sua autoestima, como possibilita às crianças melhor conhecimento, em particular do folclore e da herança cultural do país.

Os programas para a terceira idade, assim como as Universidades são compreendidas como espaço capazes de ampliar os relacionamentos sociais extrafamiliares dos idosos, propiciar novas experiências e possibilidades de aquisição de conhecimento (DEBERT, 2004, p. 246)

Tanto nos estabelecimentos de ensino público como de ensino privado, merece destaque a iniciativa de instituição da Universidade da Terceira Idade. Para freqüentá-la, a pessoa idosa não precisa ter curso universitário. Em muitas universidades, os idosos assistem às aulas e delas participam como estudantes universitários regularmente matriculados. Essa transmissão de conhecimentos e essa interação na sociedade é extremamente salutar.

A população idosa também tem sido um forte agente impulsionador do turismo no período "entre férias" - o que possibilita que os hotéis e outros centros de recreação mantenham pessoal empregado durante todo o ano para atender a essa clientela.

Por isso, as pessoas da terceira idade estão sendo

descobertas como nova fatia de mercado consumidor, estão postos diante de uma sociedade em movimento, no acelerado ritmo de mudança tecnológica, intensificação paroxísmica da comunicação (MOTTA, 1999b, p. 209).

Segundo Cabral (2001) há, principalmente, um tipo de solidariedade incondicional por parte das pessoas da terceira idade. E é esse sentimento que as faz:

- acolher em suas casas filhos casados ou separados;
- ajudar os filhos de todas as maneiras possíveis, quando as dificuldades os atingem, principalmente nas situações de enfermidade e desemprego;

- sentir que a reciprocidade e a solidariedade é suportada pelo lado que se considera mais frágil;

- ocupar grande parte do tempo para atender às demandas de filhos e netos;

- auxiliar a família, com trabalho, no apoio doméstico;

- dar um espaço no terreno, quando possui, para a construção de moradia para os filhos e netos, sendo este, um procedimento moralmente estabelecido.

Acrescente-se que a solidariedade dá compreensão fecunda à integração social do idoso (SOUTO, 1999).

A solidariedade esperada pelas pessoas idosas é a compreensão do outro, é saber que seus filhos estão bem, receber deles carinho e atenção e, quando necessário, receber tanto apoio emocional como ajuda material (CABRAL, 2001).

\section{OS JAPONESES E SEUS DESCENDENTES: O CUIDADO COM A PESSOA IDOSA E AS REDES DE SOLIDARIEDADE}

Além da legislação, há a considerar, em relação aos nikkeis residentes no Brasil e aqueles moradores no Japão que:

- há uma herança histórico-cultural de quase um século, uma verdadeira memória congelada dos migrantes de origem japonesa e seus descendentes no Brasil;

- na época da migração dos japoneses para o Brasil, no Japão, o idoso/a era respeitado/a e ouvido/a, prática que se mantém até hoje no Brasil;

- ao filho mais velho competia a responsabilidade e cuidados com a pessoa idosa, isto é, na falta ou impossibilidade dos pais, ele respondia e responde pela família;

- o filho mais velho fez e faz todo empenho possível no trabalho, em geral na pequena produção agrícola ou como feirante, para deixar espaço para os irmãos mais moços estudarem. Em função dessa abdicação e apoio aos membros da família, em geral, como recompensa, o filho mais velho herda a terra ou patrimônio urbano;

- é de responsabilidade do filho mais velho (ou de sua esposa), os cuidados com os pais. No Brasil, é raro alojar os pais em casas de repouso. Entretanto, quando isso acontece, eles recebem visitas freqüentes das famílias - prática abandonada pelos japoneses do Japão. 
As redes de solidariedade de nikkeis brasileiros no Japão são expressas sob várias formas. Na escola, mães que não trabalham são voluntárias para apoiar os filhos e os outros migrantes - inclusive para protegê-los contra freqüentes atos de violência praticados pelos colegas. Outro apoio importante das mães voluntárias diz respeito ao ensino, pois as crianças ingressam na escola de acordo com a idade e não a série, em conformidade com o conhecimento estabelecido e o da língua japonesa.

Além disso, há vários outros fatores que impulsionam a solidariedade. Como os pais permanecem muito tempo fora de casa, motivados pela necessidade de trabalhar, dedicam pouca atenção às crianças nas suas atividades escolares. Essa situação se agrava ainda mais com o desconhecimento da língua, que geralmente justifica o abandono da escola por $36 \%$ dos filhos de migrantes.

Há gestos de solidariedade por ocasião das festas, em particular no carnaval; na comida compartilhada; na oferta do emprego/ocupação; e até mesmo no empréstimo da fita de vídeo que traz novelas brasileiras gravadas. É comum compartilhar o envio de mensagens pela Internet. Mas a maioria das pessoas recebe ou envia notícias por telefone $(80 \%)$ e apenas $10 \%$ se comunicam por cartas. Como $50 \%$ dos migrantes (homens e mulheres) no Japão são casados, a solidariedade das avós do Brasil expressa-se no cuidado dos filhos do casal que parte. Merece destaque o fato de que, em geral, primeiro migra o homem, depois a mulher e - bem mais tarde - as crianças.

Por fim, não é rara nova união no Japão, tanto por parte do homem como da mulher, e o abandono dos filhos na casa dos pais, ou com a mulher que não migrou. $\mathrm{O}$ que acontece mais frequientemente é que o homem - que atravessou o oceano em busca do "Eldorado" - abandone a mulher que o espera no Brasil.

\section{A SOLIDARIEDADE INTERGERACIONAL CONVIVE MUITO POUCO COM O CAPITAL NO JAPÃO DE HOJE}

Hoje, os japoneses que vivem no Japão medem a solidariedade pelo capital e ela pode expressar-se sob várias formas. Lá, os que se aposentaram pela Previdência Social recebem menor assistência por parte da família. A assistência médica é de boa qualidade e, dependendo do caso, os idosos também recebem assistência de uma enfermeira paga pelo Estado, pois os filhos não têm tempo de dar atenção aos pais.
O grande problema surge quando os mais velhos não podem mais morar sozinhos e são encaminhados para um "asilo/casa de repouso", pois a família que trabalha "não tem tempo para cuidar da pessoa idosa porque tem que trabalhar". Quando esse fato ocorre, os idosos, nas "casas de terceira idade", preferem os cuidados de pessoas que já moraram no Brasil, pois são mais atenciosas, mais afáveis, mais respeitosas, mais carinhosas.

Anotou-se depoimento de um turista japonês visitando uma "casa de repouso" no Brasil: "No Brasil, a família vai visitar o idoso na ‘casa de repouso'. No Japão, a família vai depositar o velho no asilo e vai buscá-lo quando recebe o telefonema avisando que ele morreu". Esse fato fica muito evidente no filme japonês $O$ Funeral, no qual, após o recebimento do telefonema comunicando o falecimento do idoso, o filho é, em seguida, procurado pelo agente que cuida de funerais e que resolve tudo.

A constatação de que o capital desumaniza as relações e enfraquece a solidariedade é patente no Japão. Lá, o velho dá lugar na fila ao jovem, porque este não tem tempo. Idoso tem todo o tempo!

Diante dessa realidade, o idoso passa por uma espécie de "lavagem cerebral" portadora efetivamente de uma ideologia ilusória que insiste em convencê-los de que a mudança para o Mundo Tropical lhes dará maior longevidade. Ao mesmo tempo, o Estado se desobriga/descarta dessa população que "deu sua vida" para o Japão emergir como grande potência mundial. Por essa razão, já ocorreram compras de terreno no Brasil para a construção de vilas residenciais. A Constituição Brasileira permite, que, com uma renda de até 500 dólares mensais, qualquer pessoa estrangeira pode migrar em definitivo para o Brasil, não importando a idade. Assim é que em Campos do Jordão (SP) e Maringá (PR), japoneses já compraram terrenos para a construção de conjuntos residenciais para idosos. No Norte da África, no Sul da Espanha, no Caribe, já é uma realidade a presença de japoneses em conjuntos habitacionais.

\section{CONSIDERAÇÕES FINAIS}

A memória congelada dos migrantes japoneses para o Brasil garantiu a persistência de uma herança cultural que vem sofrendo alteração no tempo. No Japão de hoje, homens e mulheres "não têm tempo" de cuidar de seus idosos.

No Brasil, os nikkeis ainda continuam "achando tempo" para respeitar seus idosos e cuidar bem deles. Os 
exemplos citados no texto evidenciam claramente esse fato - a tal ponto que as casas de saúde japonesas têm clara preferência por atendentes nikkeis brasileiros para cuidarem dos idosos.

A sociedade brasileira é hoje muito mais sensível e tem aberto espaços para que experiências inovadoras de solidariedade intergeracional sejam vividas. Também há grande esforço de reeducação das pessoas para com a imagem do idoso - particularmente nos grupos de convivência com jovens.

Freqüentemente a solidariedade político-social tem a duração de uma queimada, mas não resiste às cinzas para a reconstrução do que foi perdido. Falta continuidade. Assim é que, ao lado das políticas públicas, é necessário que os olhos atentos da sociedade civil garantam a aplicação, a continuidade, a permanência e a renovação das políticas públicas de interesse às pessoas idosas e reforce a solidariedade intergeracional.

A solidariedade tem um nome: mulher. A solidariedade é feminina.

Há que assumir a coragem de romper com a cultura que acha "natural" a situação de abandono que paulatinamente tem vitimizado a população idosa e mutilado sua cidadania e dignidade, e implantar/desenvolver/intensificar a solidariedade com razão e emoção, para devolver/recuperar para a pessoa idosa a herança histórica de respeito/ admiração/carinho e amor, perdidos na era do descartável. Essa construção só se realiza com uma educação que pratique a solidariedade intergeracional de respeito, de amor. Dessa forma, todos terão melhor qualidade de vida, isto é, cidadania plena (SANTOS, 1996).

\section{REFERÊNCIAS BIBLIOGRÁFICAS}

BARROS, M.L. de. Autoridade e afeto: avós, filhos e netos na família brasileira. Rio de Janeiro: Zahar, 1987.

CABRAL, B.E.S.L. Solidariedade intergeracional: uma experiência dos grupos de convivência de idosos. Especiaria - Revista da UESC, Bahia, Ilhéus, p. 25-43, 2001.

Alegria de instantes: a festa de comemoração dos(as) idosos(as). In: ÁLVARES, M.L.M; SANTOS, E.F. Olhares \& Diversidades - os estudos sobre gênero no Norte e Nordeste (Brasil). GEPEM/CFCH/UFPA, Redor N/NE, 1999. p. 193-200.

CAIADO, A.S.C. A emigração internacional de brasileiros: o sentido da saída. São Paulo em Perspectiva, São Paulo, Fundação Seade, v. 11, n. 4, p. 87-96, 1997.
DEBERT, G.G. Formas de gestão da velhice: Brasil e Portugal. In: COVA, A; RAMOS, N.; JOAQUIM, T. (Org.). Desafios da comparação: Família, mulheres e gênero em Portugal e no Brasil. Oeiras, Portugal: Celta Editora, 2004. p. 235-54.

FAUSTO, B. Imigração, cortes e continuidades. In: SCHWARCZ, L.M. (Org.). História da Vida Privada no Brasil, 4. Contrastes da Intimidade Contemporânea. São Paulo: Companhia das Letras, 1998. p. 13-61.

FERREIRA, R.H. O confronto dos lugares no migrante dekassegui. Dissertação (Mestrado) - Instituto de Geociências e Ciências Exatas da Unesp, Rio Claro, 2001.

FOLHA DE S.PAULO. São Paulo, 2003.

FUNDAÇÃO SEADE. São Paulo, Outrora e Agora. Informações sobre a população da capital paulista, do século XIX ao XXI. São Paulo: 2004.

SP Demográfico. Estatísticas Vitais do Estado de São Paulo. São Paulo, ano 4, n. 5, jul. 2003. (Resenha Mensal).

GALIMBERTTI, P. O caminho que o dekassegui sonhou. Cultura e subjetividade no movimento dekassegui. São Paulo: EDUC/ FAPESP/Ed. UEL, 2002.

IBGE. Atlas do Censo Demográfico, 2000. Rio de Janeiro: 2003a.

____. Censo Demográfico 2000. Rio de Janeiro: 2003b.

Censo Demográfico. Características Gerais da População. Resultados da Amostra. Rio de Janeiro: 2001.

MOTTA, A.B. Mulheres de mais idade. In: ÁLVARES, M.L.M; SANTOS, E.F. Olhares \& Diversidades - os estudos sobre gênero no Norte e Nordeste (Brasil). GEPEM/CFCH/UFPA, Redor N/NE, 1999a. p. 167-178.

As dimensões de gênero e classe social na análise do envelhecimento. In: DEBERT, G.G. (Org.). Cadernos PaguGênero em Gerações, 13. Campinas, Núcleo de Estudos de Gênero Unicamp, 1999b. p. 191-221.

PEIXOTO, C.E. A imagem da velhice nas telas do cinema documentário. In: DEBERT, G.G. (Org.). Cadernos Pagu - Gênero em Gerações, 13. Campinas, Núcleo de Estudos de Gênero - Unicamp, 1999. p. 357-369.

REVISTA MADE IN JAPAN, n. 79, 2004.

\section{REVISTA MADE IN JAPAN, 2003.}

ROSSINI, R.E. A interculturalidade na metrópole: os velhos e os novos imigrantes internacionais. In: CARLOS, A.F.; OLIVEIRA, A.U. (Org.). Geografias de São Paulo: representação e crise da metrópole. São Paulo: Contexto, 2004. p. 343-368.

. Os dekasseguis do Brasil foram para o Japão e lá estão criando raízes. Revista GEOUSP, espaço e tempo, São Paulo, Ed. FFLCH/USP, n. 14, p. 65-76, 2003.

SAKURAI, C. Romanceiro da imigração japonesa. São Paulo: Nobel, 1987.

SALES, T. O trabalhador brasileiro no contexto das novas migrações internacionais. In: PATARRA, N.L. (Org.) Emigração e imigração internacionais no Brasil Contemporâneo. 2. ed. São Paulo: ABC/ Funap, 1996.

SANTOS, M. A natureza do espaço: técnica e tempo, razão e emoção. São Paulo: Hucitec, 1996. 
A Memória Congelada do Imigrante: a SOlidariedade intergeracional ...

SASAKI, E.M. Os dekasseguis retornados. Revista Brasileira de Estudos Populacionais, Abep, v. 13, n. 1, 1996.

SOUTO, E.M. Neve na serra: os grupos de convivência de idosos com o espaço alternativo de sociabilidade feminina. In: ÁLVARES,

M.L.M; SANTOS, E.F. Olhares \& Diversidades - os estudos sobre gênero no Norte e Nordeste (Brasil). GEPEM/CFCH/UFPA, Redor N/NE, 1999. p. 179-192.

TOMA, C.Y. A experiência feminina dekassegui. Um olhar sobre a subjetividade no processo migratório. Londrina: Ed. UEL, 2000.

YOSHIOKA, R. Questões relacionadas à educação de filhos de dekasseguis. 28 jan. 2002. Mimeografado.
Ohmo, 1995

Porque migramos do e para o Japão. São Paulo: Massao

Rosa Ester Rossini: Professora Titular do Departamento de Geografia da Faculdade de Filosofia, Letras e Ciências Humanas da Universidade de São Paulo. Assessora do CNPq e Assessora Científica da Fundação de Amparo à Pesquisa dos Estados de: SP; RJ; PE; MG; AM e DF.

Artigo recebido em 11 de abril de 2005

Aprovado em 12 de maio de 2005. 